\title{
Polysialylated-neural cell adhesion molecule (PSA-NCAM) in the human trigeminal ganglion and brainstem at prenatal and adult
}

\author{
ages \\ Marina Quartu*†, Maria Pina Serra ${ }^{\dagger}$, Marianna Boi, Viviana Ibba, \\ Tiziana Melis and Marina Del Fiacco ${ }^{\dagger}$
}

Address: Department of Cytomorphology, University of Cagliari, Cittadella Universitaria di Monserrato, Monserrato (Cagliari), Italy

Email: Marina Quartu* - quartu@unica.it; Maria Pina Serra - mpserra@unica.it; Marianna Boi - mariannaboi@tiscali.it;

Viviana Ibba - viviana.ibba@unica.it; Tiziana Melis - tiziana.melis@unica.it; Marina Del Fiacco - dfiacco@unica.it

* Corresponding author †Equal contributors

Published: 6 November 2008

BMC Neuroscience 2008, 9:108 doi:10.1/86/147|-2202-9-108

This article is available from: http://www.biomedcentral.com/l 47/-2202/9/108

(C) 2008 Quartu et al; licensee BioMed Central Ltd.

This is an Open Access article distributed under the terms of the Creative Commons Attribution License (http://creativecommons.org/licenses/by/2.0), which permits unrestricted use, distribution, and reproduction in any medium, provided the original work is properly cited.
Received: 25 July 2008

Accepted: 6 November 2008

\begin{abstract}
Background: The polysialylated neuronal cell adhesion molecule (PSA-NCAM) is considered a marker of developing and migrating neurons and of synaptogenesis in the immature vertebrate nervous system. However, it persists in the mature normal brain in some regions which retain a capability for morphofunctional reorganization throughout life. With the aim of providing information relevant to the potential for dynamic changes of specific neuronal populations in man, this study analyses the immunohistochemical occurrence of PSANCAM in the human trigeminal ganglion (TG) and brainstem neuronal populations at prenatal and adult age.

Results: Western blot analysis in human and rat hippocampus supports the specificity of the anti-PSA-NCAM antibody and the immunodetectability of the molecule in postmortem tissue. Immunohistochemical staining for PSA-NCAM occurs in TG and several brainstem regions during prenatal life and in adulthood. As a general rule, it appears as a surface staining suggestive of membrane labelling on neuronal perikarya and proximal processes, and as filamentous and dot-like elements in the neuropil. In the TG, PSA-NCAM is localized to neuronal perikarya, nerve fibres, pericellular networks, and satellite and Schwann cells; further, cytoplasmic perikaryal staining and positive pericellular fibre networks are detectable with higher frequency in adult than in newborn tissue. In the adult tissue, positive neurons are mostly small- and medium-sized, and amount to about $6 \%$ of the total ganglionic population. In the brainstem, PSA-NCAM is mainly distributed at the level of the medulla oblongata and pons and appears scarce in the mesencephalon. Immunoreactivity also occurs in discretely localized glial structures. At all ages examined, PSA-NCAM occurs in the spinal trigeminal nucleus, solitary nuclear complex, vestibular and cochlear nuclei, reticular formation nuclei, and most of the precerebellar nuclei. In specimens of different age, the distribution pattern remains fairly steady, whereas the density of immunoreactive structures and the staining intensity may change and are usually higher in newborn than in adult specimens.

Conclusion: The results obtained show that, in man, the expression of PSA-NCAM in selective populations of central and peripheral neurons occurs not only during prenatal life, but also in adulthood. They support the concept of an involvement of this molecule in the structural and functional neural plasticity throughout life. In particular, the localization of PSA-NCAM in TG primary sensory neurons likely to be involved in the transmission of protopathic stimuli suggests the possible participation of this molecule in the processing of the relevant sensory neurotransmission.
\end{abstract}




\section{Background}

The polysialylated form of the cell surface glycoprotein neural cell adhesion molecule (PSA-NCAM) is a dynamically regulated product of post-translational modification of NCAM $[1,2]$. Due to its large excluded volume, PSA can produce a sufficient physical hindrance between apposing membranes to attenuate intercellular adhesion $[2,3]$. The highest expression of PSA-NCAM occurs in the developing nervous system, where it is generally considered a promoter of neural plasticity, allowing migration of neural and nonneural precursors and facilitating axonal pathfinding and synaptogenesis $[4,5]$. In the normal adult brain of experimental animals NCAM generally displays low levels of polysialylation [6], with the exception of limited areas such as the hippocampus, the hypothalamus, the olfactory cortex and terminal regions of primary sensory afferents, which are believed to maintain a capability for morphological reorganization throughout life [7-10]. The PSA-NCAM levels and distribution have been shown to increase in learning and memory [11-13], chronic stress conditions [14-16] and several lesion models such as ischemia, epilepsy, brain trauma, and transected/crushed peripheral nerves [2,17-22]. Interestingly, the potential of PSA-NCAM expressing cells in promoting brain tissue repair [23-25] and a role for this molecule in neuroprotection [26] have been pointed out.

Data regarding the occurrence of the molecule in the normal human nervous system are still limited. Studies in the fetal brain focus on the localization of PSA-NCAM in discrete forebrain regions and on its role in developmental processes, such as neuronal migration and transitory axonal projections [27], and onset of myelination [28]. In the adult, evidence for the persistence of PSA-NCAM is restricted to the cerebral cortex [29-31] and peripheral nerve [32], where altered expression of the molecule has also been described in a number of neuropathological conditions [32-38]. In order to explore further the existence of neurons expressing the molecule in the human nervous system, thus providing potential for its dynamic changes and plasticity in response to environmental contests, we analysed whether PSA-NCAM occurs in the human primary sensory neurons, namely those of the trigeminal ganglion (TG), and in the morphofunctional heterogeneous populations of the brainstem. The study has been carried out by immunohistochemistry on normal tissue and conveys data on the occurrence of PSANCAM immunoreactivity in those regions at prenatal, neonatal and adult age. It may represent a basis for future analyses of pathological tissue specimens and, hopefully, for prospective applications in neuronal protection and repair. As the occurrence of PSA-NCAM and its persistence in the adult has been already shown in the human [29] and rat hippocampus $[18,20]$, so as to test the antibody specificity and gain information on the immunodetecta- bility of the molecule in autoptic versus non autoptic tissue, we also examined the detectability of PSA-NCAM in this brain region by western blot in both newborn and adult human and rat specimens.

\section{Results \\ Western blot}

In both the human and rat hippocampus tissue homogenates PSA-NCAM is immunochemically detectable as a single protein band whose level matches the expected molecular weight [39] (Figure 1). The band is present at all examined ages in both species. However its thickness and staining intensity are definitely more pronounced in the human pre- and full-term newborn versus adult tissue, as well as in the young versus adult rat tissue. A high degree of individual variability is also obvious among the adult human specimens.

\section{Immunohistochemistry}

Trigeminal ganglion

PSA-NCAM is localized to neuronal perikarya, nerve fibres in bundles and in between neurons, and satellite and Schwann cells; further, intense cytoplasmic staining and networks of positive pericellular fibres occur in adult tissue and are detectable only occasionally in the newborn one (Figures 2, 3).

At fetal age, a number of neuronal cell bodies appear surrounded by immunoreactive material, which may be interpreted as membrane labelling, though aspects reminiscent of labelled satellite cells can be found; rare neurons show a cytoplasmic staining (Figure 2A).

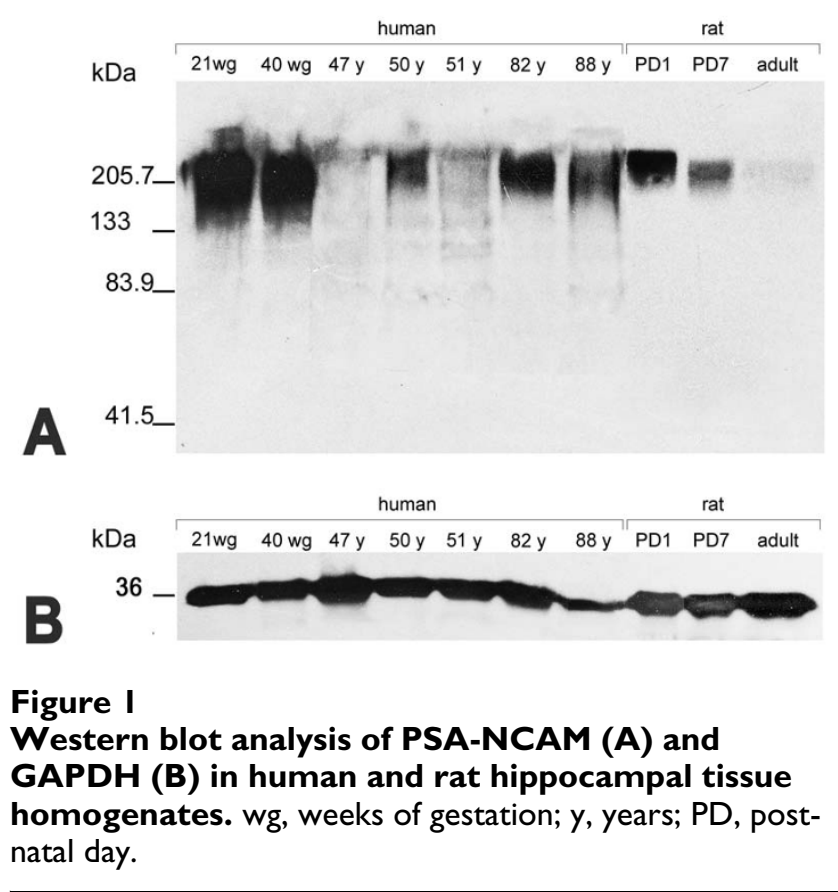




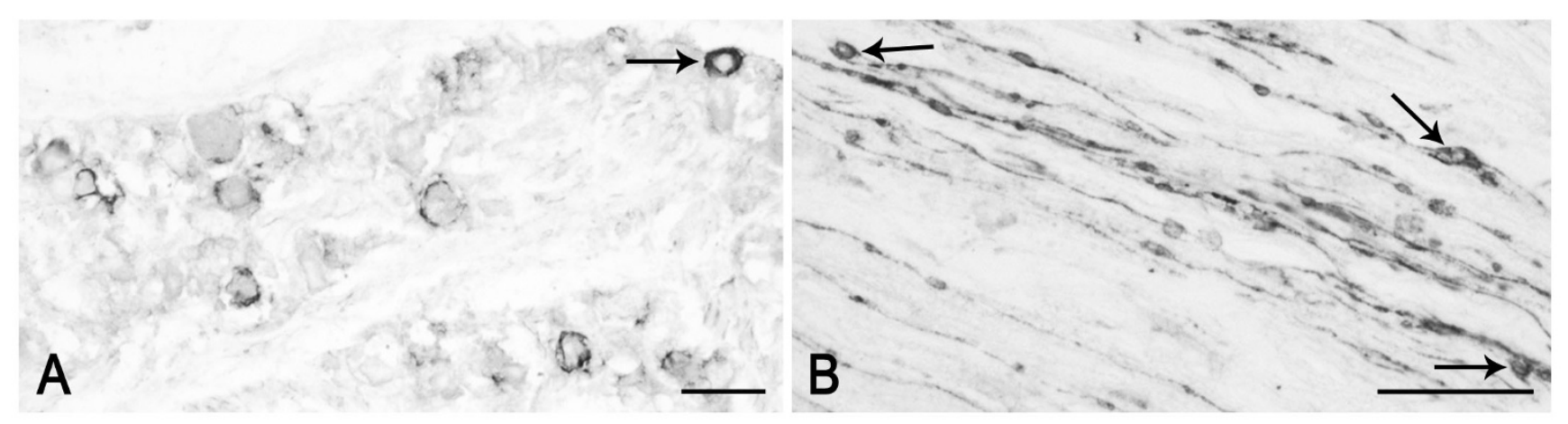

Figure 2

PSA-NCAM in the human pre-term newborn trigeminal ganglion (case 3). A: immunoreactivity of perikarya as peripheral or cytoplasmic (arrow) labelling. B: immunoreactive nerve fibres; arrows point to immunostained Schwann cells. Scale bars: $A, B=50 \mu \mathrm{m}$.

In adult tissue, several neurons show a peripheral immunoreactivity suggestive of membrane labelling (Figure $3 \mathrm{~A}, \mathrm{~B})$. However, a number of them seem surrounded by immunostained satellite cells (Figure 3C,F), which makes it difficult to unequivocally identify a membrane staining and to ascertain a neuronal labelling. On the other hand, a number of perikarya also show a cytoplasmic labelling, thus allowing a morphometric analysis. This was done considering only the cell sections where both staining of the cytoplasmic compartment and the nucleus were clearly detectable, such as those indicated by arrows in Figure $3 \mathrm{~A}, \mathrm{~B}$. In the TG specimen from an adult subject (case 6), they amount to about $6.4 \pm 0.075 \%$ of the total ganglionic population. Frequency histogram of those neurons is shown in Figure 4. About $70 \%$ of the sized neurons have a mean cell diameter ranging from $22 \mu \mathrm{m}$ to 34 $\mu \mathrm{m}$, thus falling in the class of small- and medium-sized cells, whereas the remaining of them fall in the large size range. Varicose fibres may be found either isolated or as bundles of variable density (Figure $3 \mathrm{~A}-\mathrm{C}$ ). A few non immunolabelled neuronal cell bodies appear surrounded by immunoreactive varicose nerve fibres (Figure 3D,E).

\section{Brainstem}

PSA-NCAM is mainly distributed at the level of the medulla oblongata and pons and appears scarce in the mesencephalon. The distribution pattern is uneven and remains fairly steady in specimens of different age, though changes in the density of immunoreactive structures and in the staining intensity may occur in newborn compared to adult specimens, as in the spinal trigeminal nucleus, caudal part (see Figures 5, 6). The vast majority of PSANCAM-immunolabelled structures appear as neuronal cell bodies and processes showing mainly a peripheral immunoreactivity suggestive of membrane labelling. Immunoreactivity also occurs in discretely localized glial structures, such as the dorsal median septum and the ependymal lining (Figure 5A,C). Moreover, in the latter, immunostained varicose thread-like elements may be seen running across the ependyma in a basoapical direction (Figure 5C).

The trigeminal sensory nuclear complex shows an uneven distribution of immunoreactive elements. At all ages examined, PSA-NCAM is restricted to the spinal trigeminal nucleus (Figures 5, 6, 7A), where it is represented by neuronal cell bodies and processes, and is virtually absent in the principal and mesencephalic nuclei. At fetal age, the immunoreactivity labels fibres in the spinal tract of the trigeminal nerve (Figure 5A) and in the spinal nucleus pars caudalis, where a rich plexus and neuronal cell bodies occur in the substantia gelatinosa (Figure $5 \mathrm{~A}, \mathrm{~B}$ ), and in the pars interpolaris (Figure 7A). In adult tissue, the immunostaining persists in the substantia gelatinosa whereas the spinal tract and the magnocellular subnucleus harbor rare elements (Figure 6A,C).

At caudal level of the medulla oblongata, besides the spinal trigeminal nucleus which harbors the bulk of immunoreactivity, the remaining grey substance shows a very light to moderate immunostaining in the territory of the supraspinal, central reticular and lateral reticular nuclei. Close to the ventral surface of the anterior funiculus, a band of intensely immunoreactive nerve fibres can be observed (Figure 5A). More rostrally, at the level of the pyramidal decussation, the gracile, external cuneate and commissural nuclei show a moderate immunolabelling in form of loose plexuses of filamentous and dot-like elements. A moderate diffuse immunostaining is detectable in the area postrema. Above the obex, at the level of the inferior olive, the tegmentum shows several areas of intense to moderate immunoreactivity encompassing both cranial nerve and reticular formation nuclei (Figures $7,8,9)$. At all ages examined, neuronal perikarya and 


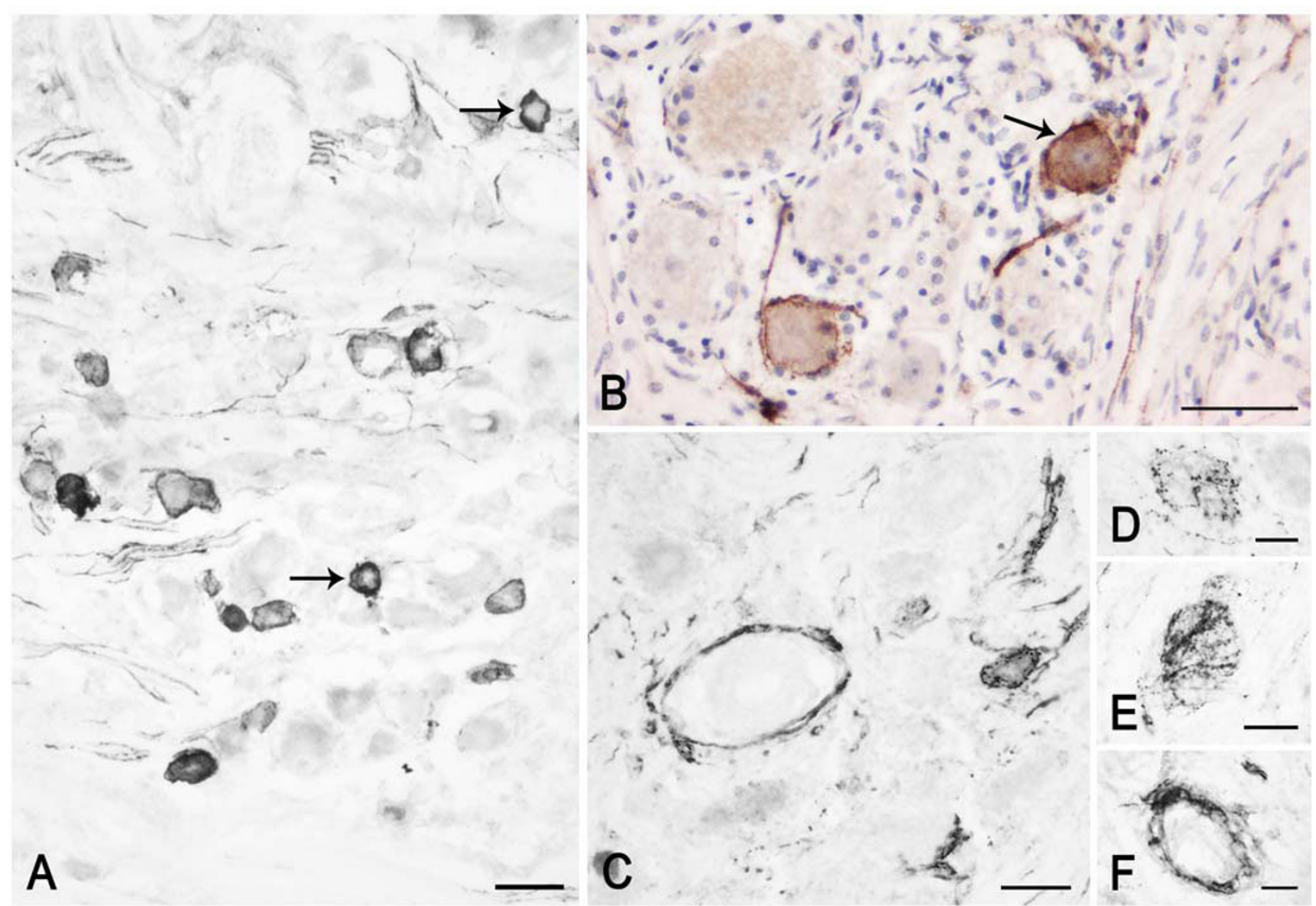

\section{Figure 3}

PSA-NCAM in the human adult trigeminal ganglion (A, B: case 5, C-F: case 10). A-C: immunostained perikarya and nerve fibres; in B, a tissue section immunostained for PSA-NCAM and co-stained with modified Mayer's hematoxylin is shown. Arrows in A and B point to PSA-NCAM immunostained neurons whose nucleus is clearly detectable. C, F: the immunolabelling appears localized to the satellite cells surrounding non immunoreactive neurons. $D$, E: pericellular varicose arborisations around non immunoreactive neurons. Scale bars: $A-C=50 \mu \mathrm{m} ; D=25 \mu \mathrm{m} ; E, F=20 \mu \mathrm{m}$.

plexuses of labelled nerve fibres can be observed in the solitary nuclear complex (Figures 7A, 9A,B), the vestibular (Figures 7A, 9C,D) and cochlear nuclei (Figure 7A,B), and the dorsal motor nucleus of the vagus nerve (Figure 7A, 9F). While its immunoreactivity is scarce in the newborn (Figure 7A), in the adult, the hypoglossal nucleus shows a moderate immunostaining in form of nerve fibre plexuses surrounding non immunoreactive neuronal cell bodies (Figure 9E). Positive fibre networks and peripherally labelled neurons are located in the intercalatus and prepositus hypoglossi (Figure $7 \mathrm{~A}, \mathrm{C}$ ), the paramedian reticular (Figure 7A), the raphe obscurus (Figure 7A, 9G), the gigantocellular, the central reticular, the intermediate reticular and the lateral reticular nuclei (Figure 7A). The olivary nuclear complex shows a diffuse staining in the neuropil at all ages (Figure 8A) with some small cell bodies in adult specimens. At fetal age, the white matter sur- rounding the inferior olive harbors isolated large, intensely stained neurons which extend dendritic branches towards the nucleus (Figure $8 \mathrm{~B}$ ). The arcuate nucleus appears intensely labelled (Figure 8A). In newborn specimens, the pyramidal tract is moderately stained (Figure 8A). Nerve fibres, isolated or grouped in small bundlets, occur across the medial lemniscus (Figure 8A).

In the pons, bundles of strongly immunoreactive nerve fibres run in the eighth cranial nerve and reach the pontine territory of the vestibular and cochlear nuclei, which harbor immunoreactive cell bodies. In the newborn, at caudalmost levels, the oral part of the dorsal paramedian nucleus (Figure 8C) shows an intense immunoreactivity due to positive neuronal perikarya and processes (Figure $8 \mathrm{D})$. The subependymal grey contains a light punctate labelling throughout. In the adult, a diffuse weak staining 


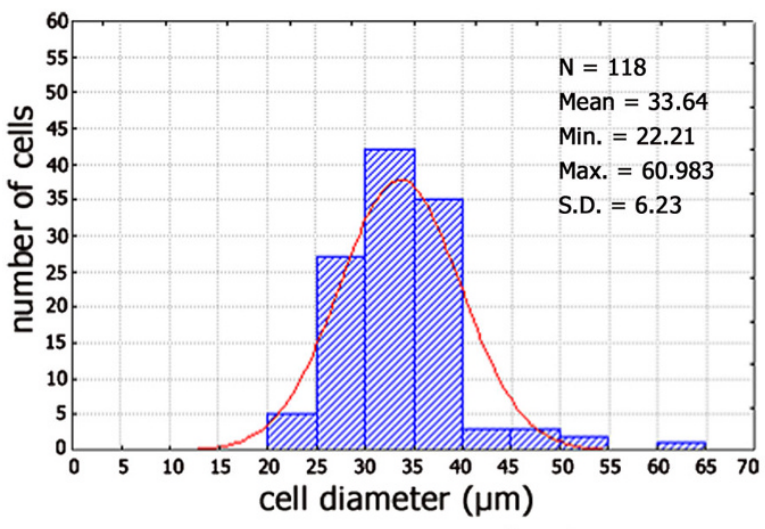

\section{Figure 4}

Size frequency histogram of PSA-NCAM immunoreactive neurons in human trigeminal ganglion from an adult subject (case 5). Cells present in 6 sections were measured. $x$-Axis values represent the mean cell diameters expressed in $\mu \mathrm{m} ; y$-axis reports values of relative percent frequency. Curve superimposed on the histogram represent the theoretical normal distribution.

is also appreciable in the locus caeruleus neuropil in between the unstained pigmented neurons. The caudal pontine, gigantocellular, parvocellular, reticulotegmental, and oral pontine reticular nuclei contain sparse neuronal cell bodies with peripheral membrane labelling and rare punctate and filamentous elements. The pontine nuclei show an intense labelling due to peripherally stained neuronal perikarya and a meshwork of thin filamentous and punctate elements in between them. Labelled nerve fibres, isolated or in bundlets, occur across the medial longitudinal fasciculus, the medial lemniscus and the lateral lemniscus.

In the quadrigeminal plate, sparse neuronal perikarya occur in the external and pericentral nuclei of the inferior colliculus, the intercollicular region and the superior colliculus. A diffuse immunostaining, occasionally localized to neuronal perikarya, occurs in the periacqueductal grey and in the territory of the median and dorsal raphe nuclei. Only in adult tissue a diffuse immunostaining can be observed in the substantia nigra. The cerebral peduncle harbors transversely sectioned labelled fibres. Close to the ventral surface of the caudal mesencephalon, positive nerve fibres form a small area of dense immunoreactivity located along the lateral edge of the interpeduncular fossa.

\section{Discussion}

The results obtained indicate that in the human nervous system a subpopulation of the TG primary sensory neurons and several regions of the brainstem express PSA-
NCAM throughout life. Centrally, the sialylated protein appears associated with most of the sensory nuclei, in agreement with findings on laboratory animals and the concept that, in these regions, the expression of growthrelated proteins may subserve structural reorganization and synaptic plasticity in response to afferent activity $[18,40]$ throughout life [20]. As for the spinal trigeminal sensory system, occurrence of the growth-associated protein-43 (GAP-43) has been reported in both the sensory ganglion and the central nuclei [41]. The localization of PSA-NCAM to the caudal part of the trigeminal spinal sensory nucleus and its changes with age are consistent with data on the rat dorsal horn spinal cord showing that PSANCAM is more widely expressed during embryonic and early postnatal than in adult life, when it is confined to the superficial laminae $[42,43]$. Such a discrete central localization of the molecule together with the morphometric characteristics of the immunoreactive trigeminal primary sensory neurons point to an involvement of PSA-NCAM in the functional roles of the elements drawn in the neurotransmission and processing of protophatic sensory stimuli. It is interesting that a PSA-dependent reversible loss of $\mathrm{C}$ terminals occurs in the spinal lamina II in a model of chronic neuropathic pain [10]. In this context, it has been proposed that, under injury or stress conditions, the presence of PSA allows for a local and reversible break in the afferent pathway in response to excessive stimulation and thereby could serve to protect central circuitry from chronic sensory overload [10].

PSA-NCAM has been shown in the chicken acoustic ganglion cells [8], where a role for the molecule in the ganglion neuron plasticity and in the processing of auditory information has been suggested. Afferents to the mouse ventral cochlear nucleus express high levels of PSA [10] and, similarly to the structural plasticity of nociceptive C terminals in chronic neuropathic pain [10], it has been reported that noxious acoustic insults are associated with a reversible atrophy of nerve terminals in the ventral cochlear nucleus [44-46].

Our observations also indicate that at all ages examined the dorsal vagal complex, namely the nucleus of the solitary tract, the dorsal motor nucleus of the vagus nerve, and the area postrema, contains PSA-NCAM-labelled neurons, nerve fibres and terminals. A convergent set of experimental data shows that in these areas, though visceral sensorimotor circuits are morphologically established in newborn rats $[47,48]$, intense dynamic changes of neuronal properties still occur after birth [40,49-54]. In the rat solitary tract nucleus, the overall PSA-NCAM expression decreases during the first two postnatal weeks and persists only at synapses in the adult [40]. Furthermore, PSANCAM expression has been shown to be dynamically controlled by the electrical stimulation of the vagal afferents 

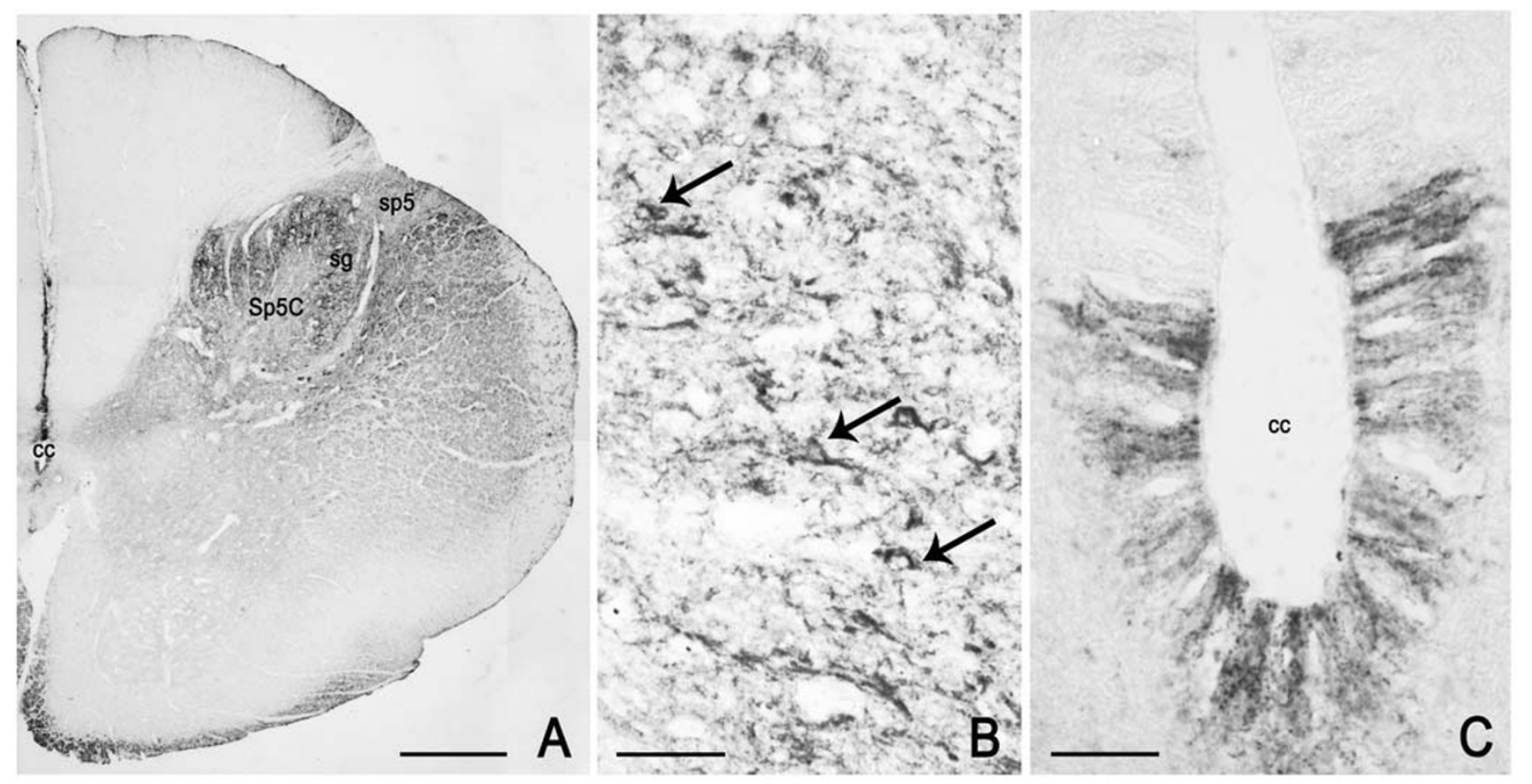

\section{Figure 5}

PSA-NCAM in the human pre-term newborn medulla oblongata, caudal level (case 3). A: panoramic view of the right half of a section at the boundary with the spinal cord. B: higher magnification of the substantia gelatinosa (sg) of the spinal trigeminal nucleus, caudal part ( $\mathrm{Sp} 5 \mathrm{C}$ ); arrows point to labelled neuronal perikarya. C: ependymal lining of the central canal. cc; central canal; sp5, spinal trigeminal tract. Scale bars: $A=500 \mu \mathrm{m} ; B=50 \mu \mathrm{m} ; C=20 \mu \mathrm{m}$.

[40] and, conversely, a repetitive stimulation of afferent fibres leads to phasic and long-term plasticity in adult animals [55].

It has been shown that the rat raphe serotonin neurons do not express PSA-NCAM [56]. Thus, it may be considered that the staining on the raphe neuronal perikarya observed in our specimens either belongs to those neurons, marking a difference with the rat species, or reflects the occurrence of positive elements impinging on the raphe neuronal somata.

PSA-NCAM occurs in most of the precerebellar nuclei, which act as a gate for the input to the cerebellum. Its expression appears particularly robust in nuclei which play a critical role in eye movement control, such as the intercalatus and prepositus hypoglossi nuclei and the paramedian reticular nucleus $[57,58]$.

PSA-NCAM-related neuroplasticity may also involve glial cells. Several lines of evidence indicate that PSA-NCAM plays a permissive role for the structural remodelling of neuronal and glial cells, particularly in the neuroendocrine system, where PSA-NCAM appears to control the retraction of the glial processes in the hypothalamo-neu- rohypophysial system $[18,59]$. Moreover, changes in PSANCAM in the avian ciliary ganglion after axonal injury also involve perineuronal satellite cells [60]. In agreement with the steric hindrance caused by the molecule $[2,3]$, the occurrence of PSA-NCAM in the TG may indicate sites of detachment between the neuronal surface and its glial ensheatment. Dynamic changes, such as remodelling of the perikaryal surface that may be operated via other growth-related proteins such as GAP-43 [61], may be facilitated by this effect. As for the finding of PSA-NCAM-positive ependymal cells in the central canal lining, it is possible that we are observing a subpopulation of glial cells which, as recently suggested in the human brain [62], during gestation and up to early infancy remains undifferentiated as potential neural progenitor cells.

\section{Conclusion}

The expression of PSA-NCAM in selective populations of central and peripheral neurons indicate that the molecule occurs both during prenatal life, suggesting a role in the development and/or maturation of neuronal circuitry, and in adulthood, when it may be indicative of the capacity to structural and functional neuronal plasticity and is possibly involved in the processing of sensory information throughout life. The neurochemical characterization 


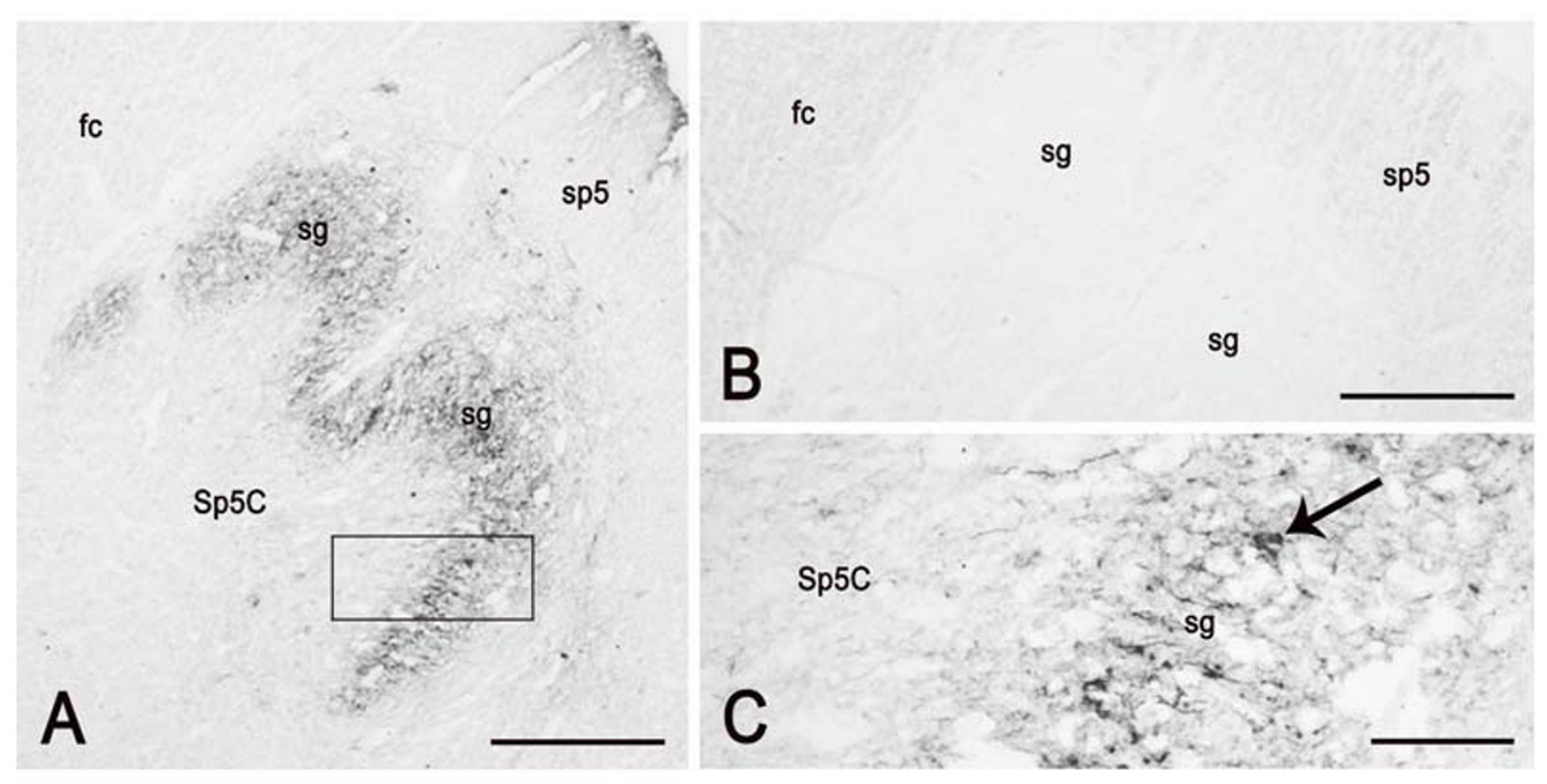

Figure 6

PSA-NCAM in the human adult medulla oblongata, caudal level (case 10). A: panoramic view of the right side spinal trigeminal nucleus, caudal part (Sp5C), at the boundary with the spinal cord. B: control immunostaining on a section semiconsecutive to that in $A$. C: higher magnification of the area framed in $A$; arrow points to a labelled neuron in the spinal nucleus substantia gelatinosa (sg). sp5, spinal trigeminal tract; fc, fasciculus cuneatus. Scale bars: $A, B=500 \mu \mathrm{m} ; D=100 \mu \mathrm{m}$.

and connectivity of the PSA-NCAM-positive neurons is an important issue and deserves further investigation. The localization of PSA-NCAM in primary sensory neurons likely to be involved in the transmission of protopathic stimuli bears a specific significance as it suggests the possible participation of this molecule in the processing of the relevant sensory neurotransmission.

\section{Methods}

Specimens of trigeminal ganglion, brainstem segments, and hippocampus were obtained at autopsy from subjects of different ages, with no history of neuropathology (Table 1). The sampling and handling of human specimens conformed to the local Ethics Committee of the National Health System in compliance with the principles enunciated in the Declaration of Helsinki. The hippocampus of male Sprague-Dawley rats sacrificed by decapitation at post-natal day (PD) 1 (2 rats), PD7 (2 rats) and adult age (2 rats) was also sampled for western blot analysis and stored at $-80^{\circ} \mathrm{C}$ until required.

\section{Western blot}

Tissue blocks of hippocampus from a pre-term newborn (case 1), a full-term newborn (case 5) and five adult subjects (cases $6,7,8,11,12$ ) were collected and stored at $80^{\circ} \mathrm{C}$ until required. Human and rat tissue homogenates were prepared in $50 \mathrm{mM}$ Tris $\mathrm{HCl}, \mathrm{pH} \mathrm{7,5}$, centrifuged at $10,000 \times \mathrm{g}$ for $20 \mathrm{~min}$, resuspended in $3 \mathrm{ml}$ of Tris $\mathrm{HCl}$, $\mathrm{pH} 7,5$. Protein concentrations were determined using the Lowry method of protein assay [63] with bovine serum albumin as standard. Proteins for each tissue homogenate $(30 \mu \mathrm{g})$ diluted 1:1 in loading buffer were heated to $95^{\circ} \mathrm{C}$ for $3 \mathrm{~min}$ and separated by SDS-polyacrilamide gel electrophoresis (SDS-PAGE) using $8.5 \%(\mathrm{w} / \mathrm{v})$ polyacrilamide resolving gel. Internal molecular weight standards (Kaleidoscope Prestained Standards, Bio-Rad, Hercules, CA, USA) were run in parallel. Two gels at a time were run for Coomassie staining and immunoblotting, respectively. Proteins for immunoblotting were electrophoretically transferred on a polyvinylidene fluoride membrane (Biorad) using the Mini Trans Blot Cell (Biorad). Blots were blocked by immersion in $20 \mathrm{mM}$ Tris base and $137 \mathrm{mM}$ sodium chloride (TBS) containing $5 \%$ milk powder and $0.1 \%$ Tween 20 (TBS-T), for $60 \mathrm{~min}$ at room temperature and incubated overnight at $4{ }^{\circ} \mathrm{C}$ with the primary antibody. A mouse monoclonal antibody against PSA-NCAM (Chemicon, USA), diluted 1:5,000 in TBS containing 5\% milk powder and $0.4 \%$ Micro-O-Protect (MOP) (Boehringer Mannheim), was used as primary antiserum. After TBS-T rinse, blots were incubated for $60 \mathrm{~min}$, at room temperature, with a peroxidase-conjugated anti-mouse serum (Chemicon), diluted 1:10,000 in TBS/T. Loading 


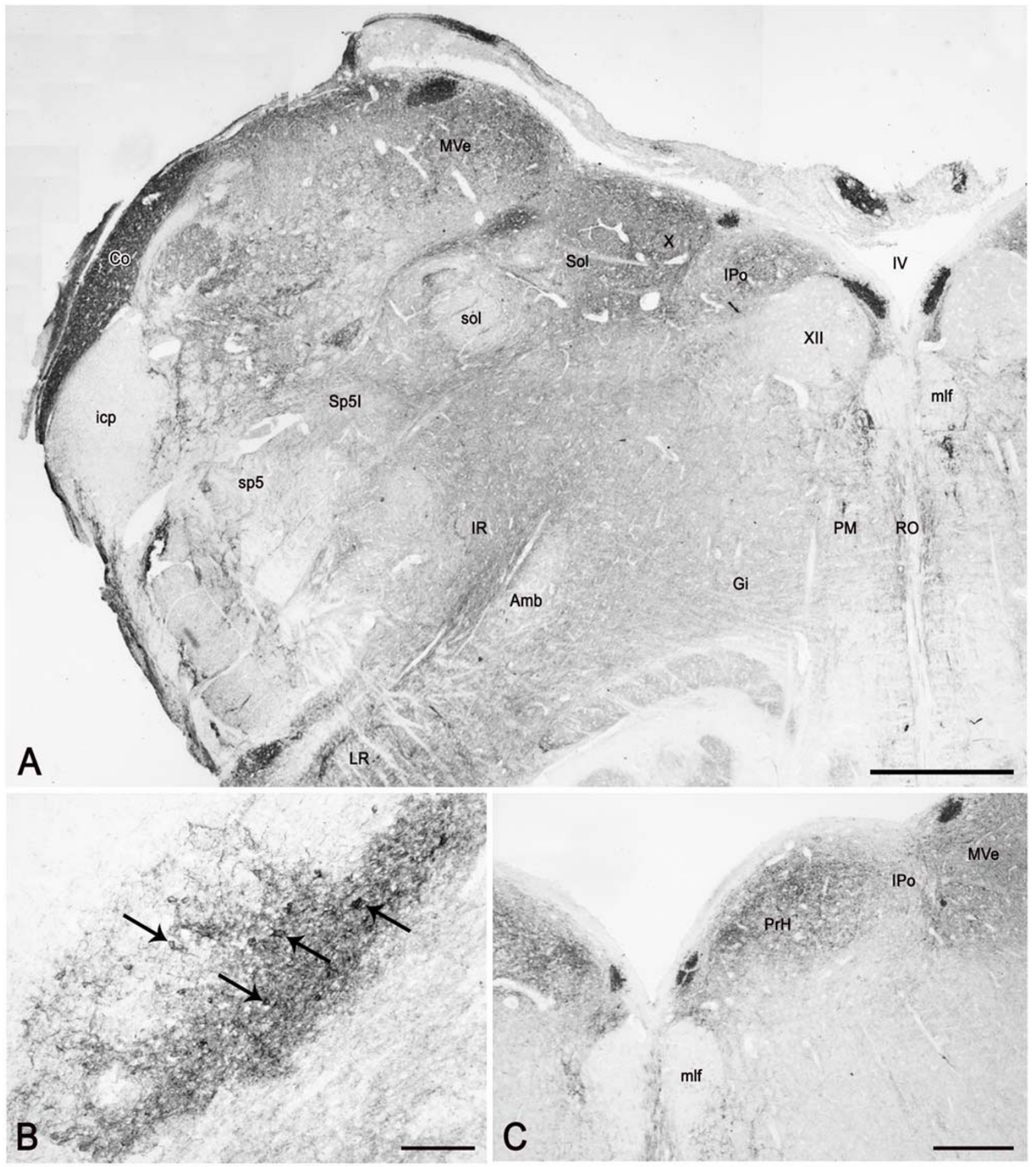

\section{Figure 7}

PSA-NCAM in the human pre-term newborn medulla oblongata, rostral level (case 3). A: panoramic view of the left side dorsal quadrant at the level of the rostral hypoglossal nucleus cell column. B: dorsal cochlear nucleus; arrows point to labelled neurons. C: low-power view of the dorsomedial field of the medulla oblongata at the level of the nucleus prepositus hypoglossi (PrH). Co, dorsal cochlear nucleus; Gi, gigantocellular nucleus; icp, inferior cerebellar peduncle; IPo, interpositus hypoglossi nucleus; IR, intermediate reticular nucleus; LR, lateral reticular nucleus; mlf, medial longitudinal fasciculus; mlf, medial longitudinal fasciculus; MVe, medial vestibular nucleus; PM, paramedian reticular nucleus; PrH, prepositus hypoglossi nucleus; RO, raphe obscurus nucleus; Sol, solitary nucleus; sol, solitary tract; sp5, spinal trigeminal tract; Sp5I, spinal trigeminal nucleus, interpolar part; IV, fourth ventricle; $X$, dorsal motor nucleus of the vagus nerve; XII, hypoglossal nucleus. Scale bars: A, $C=500 \mu \mathrm{m} ; B=100 \mu \mathrm{m}$. 

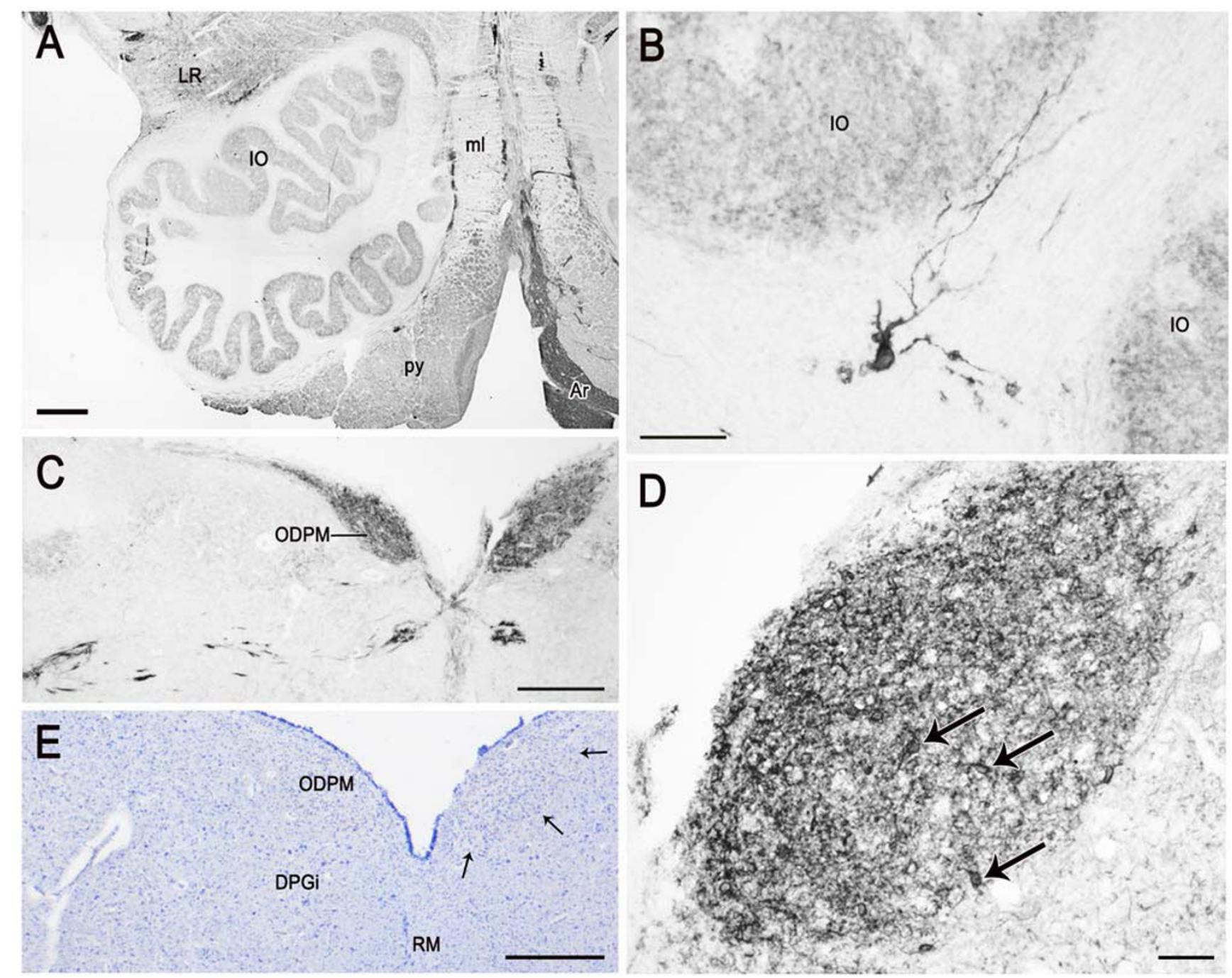

\section{Figure 8}

PSA-NCAM in the human pre-term newborn rostral medulla oblongata (A-B) and caudal pons (C-E) (case 3). A: left side ventral quadrant showing immunolabelling in the lateral reticular nucleus (LR), inferior olive (IO), pyramidal tract (Py), and arcuate nucleus (Ar). B: a positive neuron in the white matter around the inferior olive, which extends long labelled processes towards the nucleus. C: low-power view of the dorsomedial field of the medulla oblongata including the dorsal paramedian nucleus, oral part (ODPM). D: higher magnification of the right side dorsal paramedian nucleus, oral part; arrows point to positive neuronal perikarya. E: modified Mayer's hematoxylin counterstaining of a tissue section semiconsecutive to that shown in $C$ and adjacent to that shown in D; small arrows outline the cytoarchitectonic boundaries of the immunoreactive area shown in D. DPGi, dorsal paragigantocellular nucleus; ml, medial lemniscus; RM, raphe magnus nucleus. Scale bars: A, C, E $=500 \mu \mathrm{m} ; \mathrm{B}=20 \mu \mathrm{m} ; \mathrm{D}=50 \mu \mathrm{m}$.

controls were obtained by stripping and immunostaining the membranes as above, using a monoclonal mouse antibody against glyceraldehyde 3-phosphate dehydrogenase (GAPDH) (Chemicon), diluted 1:600, as primary antiserum, and a peroxidase-conjugated goat anti-mouse serum (Chemicon), diluted 1:10,000, as secondary antiserum. In order to control for non specific staining, blots were stripped and incubated with the relevant secondary antiserum. After TBS-T rinse, protein bands were visual- ized on a film (Kodak X-Omat LS, Kodak, Rochester, NY) using the ECL method (Amersham Corp.).

\section{Immunohistochemistry}

Human TG and brainstem specimens were fixed by immersion in $4 \%$ freshly prepared phosphate-buffered formaldehyde, $\mathrm{pH} 7.3$, for $4-6$ hours at $4{ }^{\circ} \mathrm{C}$, and rinsed overnight in $0.1 \mathrm{M}$ phosphate buffer (PB), $\mathrm{pH} 7.3$, containing $10 \%$ or $30 \%$ sucrose for adult and newborn spec- 


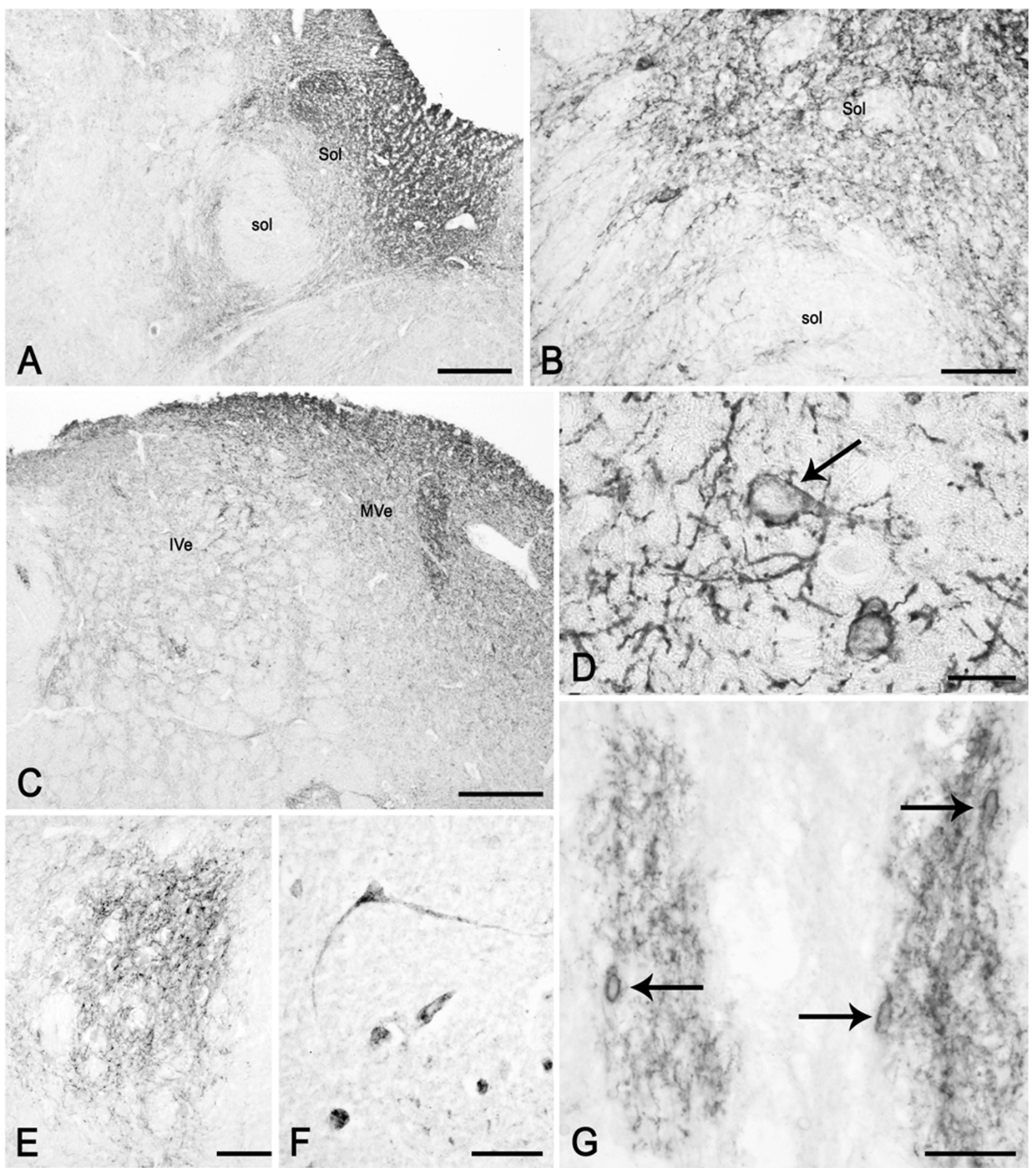

\section{Figure 9}

PSA-NCAM in the human adult medulla oblongata (case 5). A, B: left side solitary nucleus (Sol) and tract (sol). C: left side inferior (IVe) and medial vestibular (MVe) nuclei. D: a neuronal perikaryon with membrane labelling (arrow) and fibres in the neuropil of the medial vestibular nucleus. E: hypoglossal nucleus. F: dorsal motor nucleus of the vagus nerve. G: perikarya with membrane labelling (arrows) and fibre networks in the raphe obscurus nucleus. Scale bars: $A, C, E=500 \mu \mathrm{m} ; B=100 \mu \mathrm{m}$; $\mathrm{D}=20 \mu \mathrm{m} ; \mathrm{F}, \mathrm{G}=50 \mu \mathrm{m}$. 
Table I: List of specimens

\begin{tabular}{|c|c|c|c|c|c|c|}
\hline Case & Age & Sex & Cause of death & Post-mortem delay & Method & Specimen \\
\hline I & 21 w.g. & $M$ & Cardio-respiratory failure & $35 \mathrm{~h}$ & WB & Hippocampus \\
\hline 2 & 28 w.g & $\mathrm{F}$ & Cardio-respiratory failure & $37 \mathrm{~h}$ & $\mathrm{IHC}$ & Brainstem, TG \\
\hline 3 & 36 w.g. & $\mathrm{F}$ & Cardio-respiratory failure & $26 \mathrm{~h}$ & $\mathrm{IHC}$ & Brainstem, TG \\
\hline 4 & 40 w.g. & $M$ & Cardio-respiratory failure & $37 \mathrm{~h}$ & WB & Hippocampus \\
\hline 5 & $42 y$ & $M$ & Cardio-respiratory failure & $37 \mathrm{~h}$ & $\mathrm{IHC}$ & Brainstem, TG \\
\hline 6 & $47 y$ & $\mathrm{~F}$ & Pneumonitis & $50 \mathrm{~h}$ & WB, IHC & Hippocampus, brainstem, TG \\
\hline 7 & $50 y$ & $\mathrm{~F}$ & Embolysm of pulmonary artery & $26 \mathrm{~h}$ & WB & Hippocampus \\
\hline 8 & $51 y$ & $\mathrm{~F}$ & Myocardial infarction & $54 \mathrm{~h}$ & WB, IHC & Hippocampus, brainstem \\
\hline 9 & $82 y$ & $\mathrm{~F}$ & Myocardial infarction & $28 \mathrm{~h}$ & WB & Hippocampus \\
\hline 10 & $88 y$ & $M$ & Embolysm of pulmonary artery & $47 \mathrm{~h}$ & WB, IHC & Hippocampus, brainstem, TG \\
\hline
\end{tabular}

F, female; h, hours; IHC, immunohistochemistry; M, male; TG, trigeminal ganglion; w.g., weeks of gestation; WB, western blot.

imens, respectively. Cryostat sections $14 \mu \mathrm{m}$ thick were collected on chrome alum-gelatin coated slides and processed by the avidin-biotin-peroxidase complex (ABC) immunohistochemical technique. The same anti-PSANCAM antibody used for the Western blot analysis, diluted 1:400, was applied. Biotin-conjugated goat antimouse serum (Vector), diluted 1:300, was used as secondary antiserum. The reaction product was revealed with ABC (BioSpa Div.), diluted 1:250, followed by incubation with a solution of $0.1 \mathrm{M} \mathrm{PB}, \mathrm{pH} 7.3$, containing $0.05 \% 3$ 3'-diaminobenzidine (Sigma), 0.04\% nickel ammonium sulphate, and $0.01 \%$ hydrogen peroxide. Incubations with primary antiserum were carried out overnight at $4{ }^{\circ} \mathrm{C}$. Incubations with secondary antiserum and $\mathrm{ABC}$ lasted 70 and 30 minutes, respectively, and were performed at room temperature. All antisera and the $\mathrm{ABC}$ were diluted in phosphate buffered saline containing $0.2 \%$ Triton X100 (PBS/T). Control immunostainings were obtained either by omitting the primary antibody or by substituting it with normal goat serum. Alternate sections were stained with modified Mayer's hematoxylin and examined with reference to brainstem maps in Nieuwenhuys et al. [64] and Paxinos et al. [65] for the territorial identification. Slides were dehydrated, cover-slipped, and observed with an Olympus BX61 microscope. Digital images were captured with a ColorViewII Olympus telecamera.

\section{Morphometry}

Morphometric analysis was performed on TG neuronal cell profiles of digital images captured with a $20 \times$ objective magnification. Tissue sections distant from each other at least $84 \mu \mathrm{m}$ and only cells in them that obviously showed the nuclear profile were considered. Neuronal mean diameters were automatically evaluated by ImageProPlus software. Statistical parameters (mean, median, S.D.) and histograms were obtained by Statistica 6 software. The percentage of positive perikarya was calculated by the ratio of the total number of labelled cells found in three to six sections to the total number of cells found in the same sections after a modified Mayer's hematoxylin counterstaining.

\section{Authors' contributions}

MDF conceived and coordinated the study, and revised the manuscript. MQ assisted in coordinating the study, performed the statistical analysis and wrote the manuscript. MPS performed the western blot analysis and assisted in immunohistochemistry. MB performed immunohistochemistry and assisted in statistical analysis. VI and TM assisted in immunohistochemistry. All authors read and approved the final manuscript.

\section{Acknowledgements}

MDF and MQ acknowledge research funding by the University of Cagliari.

\section{References}

I. Rutishauser U, Landmesser L: Polysialic acid in the vertebrate nervous system: a promoter of plasticity in cell-cell interactions. Trends Neurosci 1996, 19:422-427.

2. Rutishauser U: Polysialic acid in the plasticity of the developing and adult vertebrate nervous system. Nat Rev Neurosci 2008, 9(I):26-35.

3. Johnson CP, Fujimoto I, Rutishauser U, Leckband DE: Direct evidence that neural cell adhesion molecule (NCAM) polysialylation increases intermembrane repulsion and abrogates adhesion. J Biol Chem 2005, 280: I 37- I 45.

4. Kiss JZ, Rougon G: Cell biology of polysialic acid. Curr Opin Neurobiol 1997, 7:640-646.

5. El Maarouf $A$, Rutishauser U: Removal of polysialic acid induces aberrant pathways, synaptic vesicle distribution, and terminal arborization of retinotectal axons. J Comp Neurol 2003, 460:203-2II.

6. Angata K, Fukuda M: Polysialyltransferases: major players in polysialic acid synthesis on the neural cell adhesion molecule. Biochimie 2003, 85:195-206.

7. Seki Y, Arai T: Distribution and possible roles of highly polysialylated neural cell adhesion molecule (NCAM-H) in the developing and adult central nervous system. Neurosci Res 1993, 17:265-290.

8. Kajikawa H, Umemoto M, Mishiro Y, Sakagami M, Kubo T, Yoneda Y: Expression of highly polysialylated NCAM (NCAM-H) in developing and adult chicken auditory organ. Hearing Res 1997, 203:123-130.

9. Theodosis DT, Bonhomme R, Vitiello S, Rougon G, Poulain DA: Cell surface expression of polysialic acid on NCAM is a prerequisite for activity-dependent morphological neuronal and glial plasticity. J Neurosci 1999, 19:10228-10236.

10. El Maarouf A, Kolesnikov Y, Pasternak G, Rutishauser U: Polysialic acid-induced plasticity reduces neuropathic insult to the cen- 
tral nervous system. Proc Natl Acad Sci USA 2005, 102:11516-11520.

II. Becker CG, Artola A, Gerardy-Schahn R, Becker T, Welzl H, Schachner $M$ : The polysialic acid modification of the neural cell adhesion molecule is involved in spatial learning and hippocampal long-term potentiation. I Neurosci Res 1996, 45: 143-152

12. Fox GB, Fichera G, Barry T, O'Connell AW, Gallagher HC, Murphy $\mathrm{KJ}$, Regan $\mathrm{CM}$ : Consolidation of passive avoidance learning is associated with transient increases of polysialylated neurons in layer II of the rat medial temporal cortex. J Neurobiol 2000, 45: $|45-| 4 \mid$.

13. Ronn LC, Berezin V, Bock E: The neural cell adhesion molecule in synaptic plasticity and ageing. Int J Dev Neurosci 2000, 18:193-199.

14. Pham K, Nacher J, Hof PR, McEwen BS: Repeated restraint stress suppresses neurogenesis and induces biphasic PSA-NCAM expression in the adult rat dentate gyrus. Eur J Neurosci 2003 17:879-886.

15. Sandi C, Merino JJ, Cordero ML, Kruyt ND, Murphy KJ, Regan CM: Modulation of hippocampal NCAM polysialylation and spatial memory consolidation by fear conditioning. Biol Psychiatry 2003, 54:599-607.

16. Nacher J, Pham K, Gil-Fernandez V, McEwen BS: Chronic restraint stress and chronic corticosterone treatment modulate differentially the expression of molecules related to structural plasticity in the adult rat piriform cortex. Neuroscience 2004, 1 26:503-509.

17. Bonfanti L, Merighi A, Theodosis DT: Dorsal rhizotomy induces transient expression of the highly sialylated isoform of the neural cell adhesion molecule in neurons and astrocytes of the adult rat spinal cord. Neuroscience 1996, 74:619-623.

18. Bonfanti L: PSA-NCAM in mammalian structural plasticity and neurogenesis. Prog Neurobiol 2006, 80:129-164.

19. Iwai M, Hayashi T, Zhang WR, Sato K, Manabe Y, Abe K: Induction of highly polysialylated neuronal cell adhesion molecule (PSA-NCAM) in postischemic gerbil hippocampus mainly dissociated with neural stem cell proliferation. Brain Res 200I, 902:288-293.

20. Emery DL, Royo NC, Fischer I, Saatman KE, Mclntosh TK: Plasticity following injury to the adult nervous system: is recapitulation of a developmental state worth promoting? J Neurotrauma 2003, 20:127|-1292.

21. Singh J, Kaur G: Neuroprotection mediated by subtoxic dose of NMDA and SH-SY5Y neuroblastoma cultures: activitydependent regulation of PSA-NCAM expression. Mol Brain Res 2005, 137:223-234.

22. Franz CK, Rutishauser U, Rafuse VF: Polysialylated neural cell adhesion molecule is necessary for selective targeting of regenerating motor neurons. J Neurosci 2005, 25:2081-2091.

23. Nguyen L, Rigo JM, Malgrange B, Moonen G, Belachew S: Untangling the functional potential of PSA-NCAM-expressing cells in CNS development and brain repair strategies. Curr Med Chem 2003, 10:2185-2196.

24. El Maarouf A, Petridis AK, Rutishauser U: Use of polysialic acid in repair of the central nervous system. Proc Natl Acad Sci USA 2006, 103:16989-16994.

25. El Maarouf A, Rutishauser U: Use of PSA-NCAM in repair of the Central Nervous System. Neurochem Res 2008 in press.

26. Duveau V, Arthaud S, Rougier A, Le Gal La Salle G: Polysialylation of NCAM is upregulated by hyperthermia and participates in heat shock preconditioning-induced neuroprotection. Neurobiol Disease 2007, 26:385-395.

27. Ulfig N, Chan WY: Expression patterns of PSA-NCAM in the human ganglionic eminence and its vicinity: role of PSA NCAM in neuronal migration and axonal growth? Cells Tissues Organs 2004, 177:229-236.

28. Jakovcevski I, Mo Z, Zecevic N: Down-regulation of the axonal polysialic acid-neural cell adhesion molecule expression coincides with the onset of myelination in the human fetal forebrain. Neuroscience 2007, 149:328-337.

29. Ní Dhúill CM, Fox GB, Pittock SJ, O'Connell AW, Murphy KJ, Regan $C M$ : Polysialylated neural cell adhesion molecule expression in the dentate gyrus of the human hippocampal formation from infancy to old age. J Neurosci Res 1999, 55:99-106.
30. Arellano Jl, DeFelipe J, Muñoz A: PSA-NCAM immunoreactivity in chandelier cell axon terminals of the human temporal cortex. Cereb Cortex 2002, 1 2:617-624.

31. Varea E, Castillo-Gómez E, Gómez-Climent MA, Blasco-lbáñez JM, Crespo C, Martínez-Guijarro FJ, Nàcher J: PSA-NCAM expression in the human prefrontal cortex. I Chem Neuroanat 2007, 33:202-209.

32. Roche P-H, Figarella-Branger D, Daniel L, Bianco N, Pellet W, Pellissier J-F: Expression of cell adhesion molecules in normal nerves, chronic axonal neuropathies and Schwann cell tumors. J Neurol Sci 1997, I 5 I:127-133.

33. Barbeau D, Liang II, Robitalille $Y$, Quirion $R$, Srivastava LK Decreased expression of the embryonic form of the neural cell adhesion molecule in schizophrenic brains. Proc Natl Acad Sci USA 1995, 92:2785-2789.

34. Mikkonen M, Soininen H, Kälviänen R, Tapiola T, Ylinen A, Vapalahti $M$, Paljärvi L, Pitkänen A: Remodeling of neuronal circuitries in human temporal lobe epilepsy: increased expression of highly polysialylated neural cell adhesion molecule in the hippocampus and the entorhinal cortex. Ann Neurol 1998, 44:923-934.

35. Mikkonen M, Soininen H, Tapiola T, Alafuzoff I, Miettinen R: Hippocampal plasticity in Alzheimer's disease: changes in highly polysialylated NCAM immunoreactivity in the hippocampal formation. Eur J Neurosci 1999, I I:1754-1764.

36. Mathern GW, Leiphart JL, De Vera A, Adelson PD, Seki T, Neder L, Leite JP: Seizures decrease postnatal neurogenesis and granule cell development in the human fascia dentata. Epilepsic 2002, 43(Suppl 5):68-73.

37. Charles P, Reynolds R, Seilhean D, Rougon G, Aigrot MS, Niezgoda A, Zalc B, Lubetzki C: Re-expression of PSA-NCAM by demyelinated axons: an inhibitor of remyelination in multiple sclerosis? Brain 2002, I 25:1972-1979.

38. Weber M, Modemann S, Schipper P, Trauer H, Franke H, Illes P, Geiger KD, Hengstler JG, Kleemann WJ: Increased polysialic acid neural cell adhesion molecule expression in human hippocampus of heroin addicts. Neuroscience 2006, 138:12/5-1223.

39. Dubois C, Figarella-Branger D, Pastoret C, Rampini C, Karpati G, Rougon G: Expression of NCAM and its polysialylated isoforms during mdx mouse muscle regeneration and in vitro myogenesis. Neuromuscul Disord 1994, 4:171-182.

40. Bouzioukh F, Tell F, Rougon G, Jean A: Dual effects of NMDA receptor activation on polysialylated neural cell adhesion molecule expression during brainstem postnatal development. Eur J Neurosci 200I, 14:1194-1202.

4I. Del Fiacco M, Quartu M, Priestley JV, Setzu MD, Lai ML: GAP-43 persists in adulthood and coexists with SP and CGRP in human trigeminal sensory neurones. Neuroreport 1994, 5:2349-2352.

42. Bonfanti L, Olive S, Poulain DA, Theodosis DT: Mapping of the distribution of polysialylated neural cell adhesion molecule throughout the central nervous system of the adult rat: an immunohistochemical study. Neuroscience 1992, 49(2):419-36.

43. Seki Y, Arai T: Highly polysialylated NCAM expression in the developing and adult rat spinal cord. Brain Res Dev Brain Res 1993, 73(I): | $41-5$

44. Bilak M, Kim J, Potashner SJ, Bohne BA, Morest DK: New growth of axons in the cochlear nucleus of adult chinchillas after acoustic trauma. Exp Neurol 1997, 147:256-268.

45. Kim J, Morest DK, Bohne BA: Degeneration of axons in the brainstem of the chinchilla after auditory overstimulation. Hear Res 1997, 103:169-191.

46. Morest DK, Kim J, Bohne BA: Neuronal and transneuronal degeneration of auditory axons in the brainstem after cochlear lesions in the chinchilla: cochleotopic and non-cochleotopic patterns. Hear Res 1997, 103:151-168.

47. Rinaman L, Levitt P: Establishment of vagal sensorimotor circuits during fetal development in rats. J Neurobiol 1993, 24:64I-659.

48. Cheng G, Zhou X, Qu J, Ashwell KW, Paxinos G: Central vagal sensory and motor connections: human embryonic and fetal development. Auton Neurosci 2004, I | 4:83-96.

49. Takemura M, Wakisaka S, Iwase K, Yabuta NH, Nakagawa S, Chen K, Bae YC, Yoshida A, Shigenaga Y: NADPH-diaphorase in the developing rat: lower brainstem and cervical spinal cord, 
with special reference to the trigemino-solitary complex. Comp Neurol 1996, 365:5 I I-525.

50. Vincent A, Jean A, Tell F: Developmental study of N-methyl-Daspartate-induced firing activity and whole-cell currents in nucleus tractus solitarii neurons. Eur J Neurosci 1996, 8:2748-2752.

5I. Vincent A, Tell F: Postnatal changes in electrophysiological properties of rat nucleus tractus solitarii neurons. Eur $J \mathrm{Neu}-$ rosci 1997, 9:1612-1624.

52. Vincent A, Tell F: Postnatal development of rat nucleus tractus solitarius neurons: morphological and electrophysiological evidence. Neuroscience 1999, 93:293-305.

53. Rao H, Pio J, Kessler JP: Postnatal ontogeny of glutamate receptors in the rat nucleus tractus solitarii and ventrolateral medulla. J Auton Nerv Syst 1997, 65(I):25-32.

54. Moyse E, Baner S, Charrier C, Coronas V, Krantic S, Jean A: Neurogenesis and neural stem cells in the dorsal vagal complex of adult rat brain: new vistas about autonomic regulations-a review. Auton Neurosci 2006, I 26-1 27:50-8.

55. Zhou Z, Champagnat J, Poon C-S: Phasic and long-term depression in brainstem nucleus tractus solitarius neurons: differing roles of AMPA receptor desensitization. J Neurosci 1997, I 7:5349-5356.

56. Brezun JM, Daszuta A: Serotonin depletion in the adult rat produces differential changes in highly polysialylated form of neural cell adhesion molecule and tenascin-C immunoreactivity. J Neurosci Res 1999, 55:54-70.

57. Hopp JJ, Fuchs AF: The characteristics and neuronal substrate of saccadic eye movement plasticity. Prog Neurobiol 2004, 72:27-53.

58. Tilikete $C$, Pélisson D: Ocular motor syndromes of the brainstem and cerebellum. Curr Opin Neurol 2008, $21: 22-28$.

59. Parkash J, Kaur G: Potential of PSA-NCAM in neuron-glial plasticity in the adult hypothalamus: role of noradrenergic and GABAergic neurotransmitters. Brain Res Bull 2007, 74:3।7-328.

60. De Stefano ME, Leone L, Paggi P: Polysialylated neural cell adhesion molecule is involved in the neuroplasticity induced by axonal injury in the avian ciliary ganglion. Neuroscience 200I, 103:1093-1104

61. Nacimiento $W$, Töpper R, Fischer A, Oestreicher AB, Nacimiento AC, Gispen WH, Noth J, Kreutzberg GW: Immunocytochemistry of B-50 (GAP-43) in the spinal cord and in dorsal root ganglia of the adult cat. J Neurocytol 1993, 22:413-424.

62. Sakakibara A, Aoki E, Hashizume Y, Mori N, Nakayama A: Distribution of nestin and other stem cell-related molecules in developing and diseased human spinal cord. Pathol Int 2007, 57:358-568.

63. Lowry OH, Rosebrough NJ, Farr AL, Randall RJ: Protein measurements with the Folin phenol reagent. J Biol Chem 195I, 193:265-275.

64. Nieuwenhuys R, Voogd J, van Huijzen C: Sistema Nervoso Centrale Piccin Editore Padova; 1980.

65. Paxinos G, Törk I, Halliday G, Mehler WR: Human homologs to brainstem nuclei identified in other animals as revealed by acetylcholinesterase activity. In The human nervous system Edited by: Paxinos G. San Diego: Academic Press, Inc; 1990:149-202.
Publish with Biomed Central and every scientist can read your work free of charge

"BioMed Central will be the most significant development for disseminating the results of biomedical research in our lifetime. "

Sir Paul Nurse, Cancer Research UK

Your research papers will be:

- available free of charge to the entire biomedical community

- peer reviewed and published immediately upon acceptance

- cited in PubMed and archived on PubMed Central

- yours - you keep the copyright
BioMedcentral 